\title{
Possible Directions of Evolution for Banking Activity in European Union under the Impact of Blockchain Technology
}

\author{
Dragoş Danțiş̧ ${ }^{1}$
}

\begin{abstract}
European Union banking industry is subject to numerous changes in the daily activities performed, having to adapt the business to a wide range of impacting factors. Among these, the blockchain technology bas a significant potential in updating the current context, aspect bighlighted by academic environment, researchers and innovation specialists.

Current research paper has the intent to identify the areas where the blockchain technology could impact the EU banking industry, analyse the scenarios and make possible praises for the evolution of business in banking.
\end{abstract}

Keywords: banking, blockechain, financial transactions, economy, innovation

JEL Classification: F00.

DOI: $10.24818 / \mathrm{REJ} / 2021 / 80 / 04$

\section{Introduction}

For many decades the space of the European Union has been an area of progress, prosperity and social welfare. This context has been linked with many factors, one being, the presence of a mature banking system, interested in supporting the economic development not only among the members of the Union, but as well with third state actors.

Like all the systems, the banking one, has witnessed periods of downfall (financial crisis) or periods of expansion, directions present at the level of the entire sector or at the level of the composing actors. With this statement we arrive to the first question of the research paper: "how many banks are in the space of the European Union or on the European continent?" in order to have an overview on the dimension of the system.

1 P.h.D. International Business and Economics, Bucharest University of Economic Studies, Bucharest, Romania, dragos.dantis@gmail.com

Year XXIV no. 80

June 2021 


\section{European Union Banking Environment}

According to the study performed by European Banking Federation [1] the 28-member states of the Union (before Brexit) have been impacted by a decrease in the number of financial institutions, trend linked to consolidation, merger or disappearance of various performers. If at the level of the year 2008 were present 8.525 credit institutions at the level of 2019 have been identified 5.981 units.

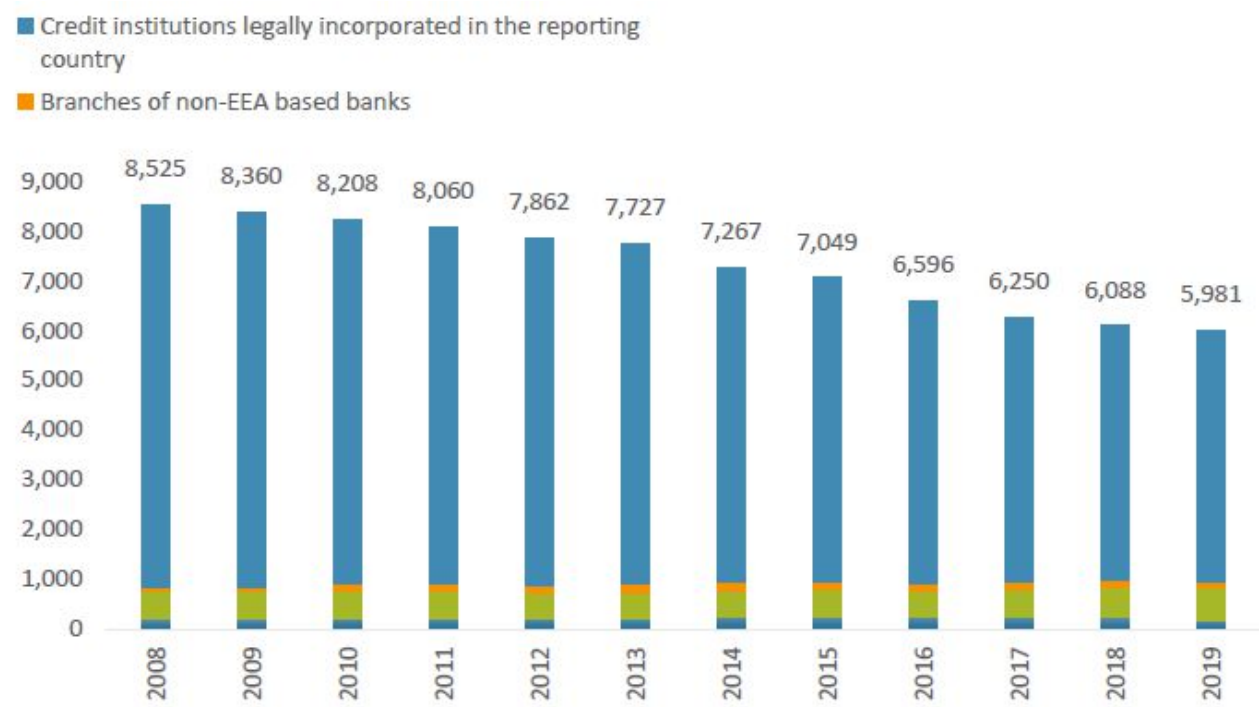

Figure 1. Credit institutions in the EU

Source: EBF - "Banking in Europe: EBF Facts and Figures 2020"

The same study, using the data of European Central Bank indicates the countries with the biggest decrease in 2019 in terms of financial entities: Germany, Austria, Poland, and Italy. Meanwhile for states like Romania, United Kingdom, Portugal, Croatia, Sweden, Netherlands are mentioned increase of units, a direction opposed to the general trend [2].

Research of the European Banking Federation sustains the idea of changing realities at the EU level in general, and banking level in particular, each of them impacted by several factors. Among the influencing items can be indicated the economical context, the technical development, permanent evolution in the field of the artificial intelligence, change in the behavior and interaction pattern of consumers towards services accepted, innovative business models or new entries. 
The banks had to participate in a new market, where the competition increased, not only among the banks, but among the banks and new comers, represented by so-called FinTech companies, or other, actors, offering services, typically in the portfolio of the credit institutions. Confronted to this new dynamic scenario, banks had to rethink the business model, understating that the "classical way" of doing banking was not guaranteeing, the development or the maintaining of the market share, many of the existing customers directing towards services put in the field by other competitive models. Many of the financial analysts considered this change a benefit for the costumers, allowing them to choose the best model to suit their needs. As a possible consequence of this disruptive approach, where banks had to reconsider their model, was the implementation of new channels of interacting and selling products to customers. This idea can be sustained by the decrease in the number of the banking branches, phenomenon, which could be linked as well to the desire of the financial institutions to reduce some of the costs associated to the functioning of the territorial units.

For practical reasons we address again to the study performed by the European Banking Federation, a valuable source for understanding the directions of the European Union banking area, showing a general decrease from 237 thousand units in 2008 to 163 thousand units in 2019 [3].

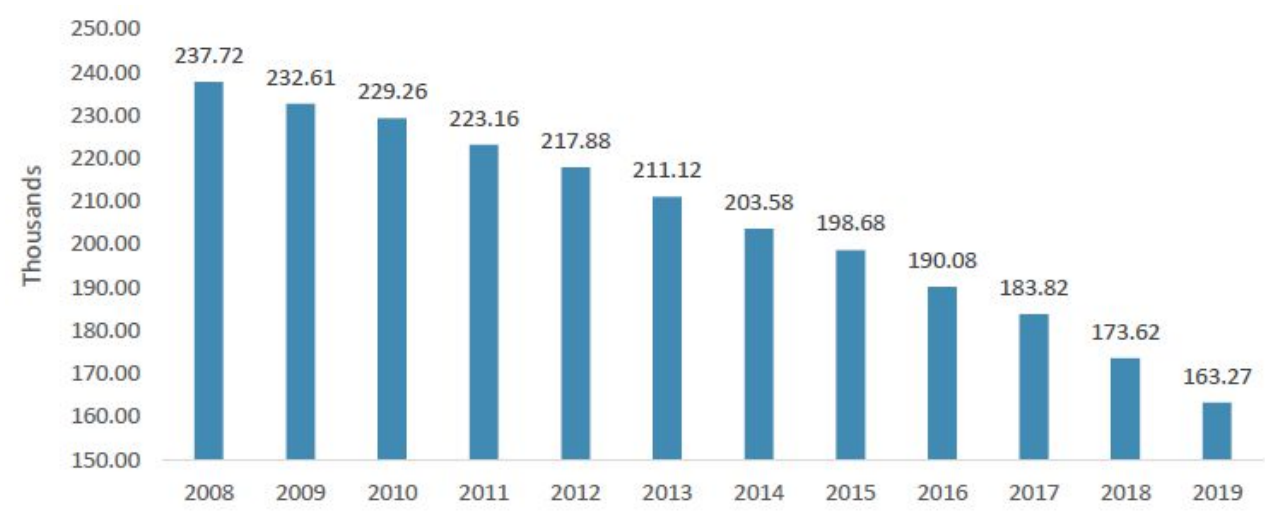

Figure 2. Evolution of domestic bank branches

Source: EBF - "Banking in Europe: EBF Facts and Figures 2020"

The technological development is influencing and will continue to influence with its components the digital evolution in banking. Impacts will be seen not only in the processes, products and services of Branches, but as well in those of the entire structure of the banks, leading to a continuous change of the environment of the credit institutions. Among the factors impacting the ecosystem of the banks can be 
indicated: internet of things, smart analytics, wearable devices, mobile banking, instant payments, robotic process automation, robotic advisors, biometrics, social media, virtual platforms, cryptocurrencies and blockchain.

\section{Progress of Blockchain Technology in European Banking Industry}

One of the new technologies with presence in various processes or services of the banking industry is represented by the blockchain. Since the appearance of the technology, there have been numerous points of view regarding its utility; nevertheless the big financial groups or even smaller players have decided to invest in its testing and development.

\subsection{Definition and Functioning of Blockchain Technology}

Blockchain or distributed ledger technology appeared several years ago and has represented a turning point in the functioning of central databases, registration of items inside a public register and confirmation or authorization of records. In simple words, it can be said, blockchain has the same impact as the Internet did and it will progress in various domains of social and economic life.

Referring to the paper published by National Institute of Standards and Technology [4] several key moments have been identified in the evolution of blockchain technology:

- in 1989 Leslie Lamport developed the Paxos protocol, followed in 1990 by a research paper, published in a later moment;

- 2008 under the pseudonym Satoshi Nakamoto appeared the paper "Bitcoin: $A$ Peer to Peer Electronic Cash System"

- 2009 establishment of the Bitcoin cryptocurrency blockchain network

As a general definition blockchain technology represents a chain of blocks of data (digital records) linked and secured using cryptography. The chain of registrations is grouped in one ledger, accessible to several users, able to add data to the blocks verify it and approve it. One of the main characteristics of the technology is the content connection among the groups of data, guaranteeing the authenticity and uniqueness of the items.

Another characteristic of the technology is the capability of each member of the network to generate content (or transaction), like in the case of cryptocurrencies and to send it to other participants of the blockchain network, without the need of an intermediary.

Year XXIV no. 80

June 2021 
Many of the specialists consider the first practical proof regarding the functioning of the Blockchain technology the creation of the first unit of Bitcoin in 2009, viewed as the first cryptocurrency. From that moment the functioning of the technology has started attracting attention and has been tested and implemented in various fields: supply chain, trading, banking, retail, governmental services, intellectual property, oil and gas, real estate, insurance, internet of things, media and entertainment, travel.

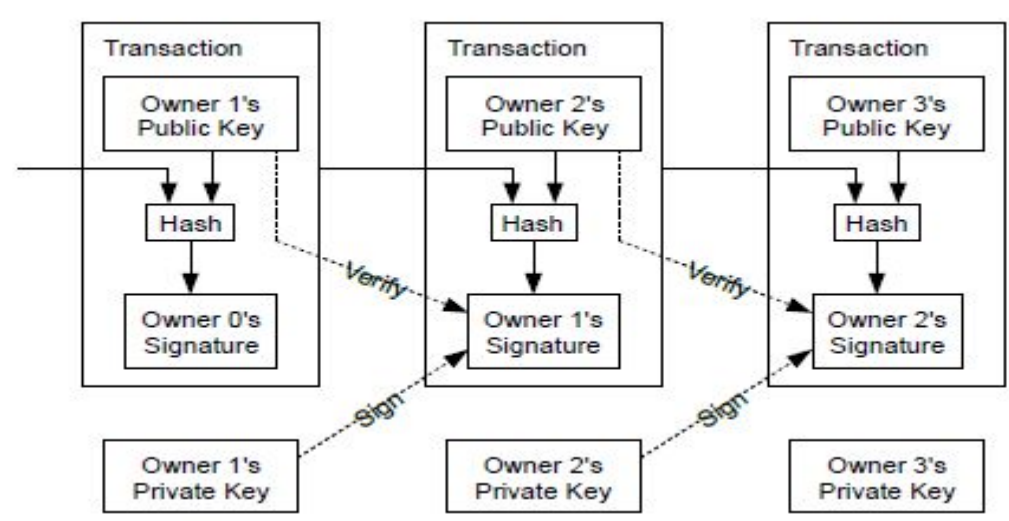

Figure 3. Blockchain technology functioning [5]

Source: Satoshi Nakamoto - "Bitcoin: A Peer-to-Peer Electronic Cash System"

The way blockchain is functioning has been seen as a strategic asset at worldwide level and a great opportunity for investments. In a press release in February 2018 the European Commission announced the launch of EU Blockchain Observatory and Forum. The official announcement quoted the opinion of Mr. Valdis Dombrovskis, Vice-President responsible for Financial Stability, Financial Services and Capital Markets Union: "Among the many technologies that are driving digital innovation, blockchain has the potential to be truly transformative for financial services and markets. The Blockchain Observatory and Forum will monitor developments and also inform our policy making [6]".

\subsection{Utilization of Blockchain Technology in Banking}

Large financial institutions or medium sized banks have been among the first players interested in testing and investing in the functionality of the blockchain technology.

Year XXIV no. 80

June 2021 
The credit institutions followed different approaches and strategies in the implementation of the technology in their portfolio of processes and services:

- addressing consultant companies to perform an initial proof-of-concept;

- testing the functioning and the benefits resulted in their own research and development divisions;

- creation of joint ventures with FinTech companies;

- investment in new start-up companies having as field of activity the blockchain;

- enrolment in big consortium like R3 [7];

- participating in initiatives launched at national level, like ABI Lab [8].

One of the first areas where banks decided to test the technology has been Payments environment, taking into consideration this has been one of the services directly targeted by the FinTech organizations.

Payments represent a strategic financial asset and would be a great opportunity for EU to use the blockchain technology to have the sector dominated by European banks. Currently this is quite difficult to achieve as the performing of a payment can take longer due to compliance checks or settlement and many of the clients are using FinTech products or transactions via cards channel. Even the European Commission stated clearly in the favour of Instant Payments extension in the Union, consolidating the payments solutions and keeping the data of the transactions inside Europe, with a higher interest in data protection and privacy laws [9].

The idea on the importance of payments as financial asset has been highlighted as well by Mr. Fabio Panetta, member of the Executive Board of the ECB at the "Future of Payments in Europe" conference in 2020. His statements were linked as well with the recent initiative launched by European Central Bank in the domain of digital euro [10].

Discussing on the actions ongoing, Mr. Fabio stated: "The ECB and the national central banks have started preliminary experimentation through four work streams. First, we will test the compatibility between a digital euro and existing central bank settlement services (such as TIPS). Second, we will explore the interconnection between decentralised technologies, such as distributed ledgers, and centralised systems. Third, we will investigate the use of payment-dedicated blockchains with electronic identity. And fourth, we will assess the functionalities of hardware devices that could enable offline transactions, guaranteeing privacy".

Year XXIV no. 80

June 2021 
Strictly related to payments is the risk of fraud, which can be mitigated through the use of blockchain technology, as the storage of transaction data in this environment benefits from increased security.

European banks and not only them are subject to numerous requirements issued by national, European or international regulatory bodies or supervisory authorities, aspect translated at practical level, in internal procedures and processes for antimoney laundering, prevention of terrorism financing, know your customer and other relevant subjects. Reunited under the general umbrella of Compliance framework and function, banks spend a significant amount of time and money in putting in place controls, training specialized personnel and reporting towards authorities. This aspect is subject of interest to the European Banking Authority, which has launched an initiative to assess the costs of financial institutions when complying with supervisory reporting requirements [11]. According to the information posted on its website by EBA, the results of the project will be sent under the form of a report (cost of compliance study) to the European Commission.

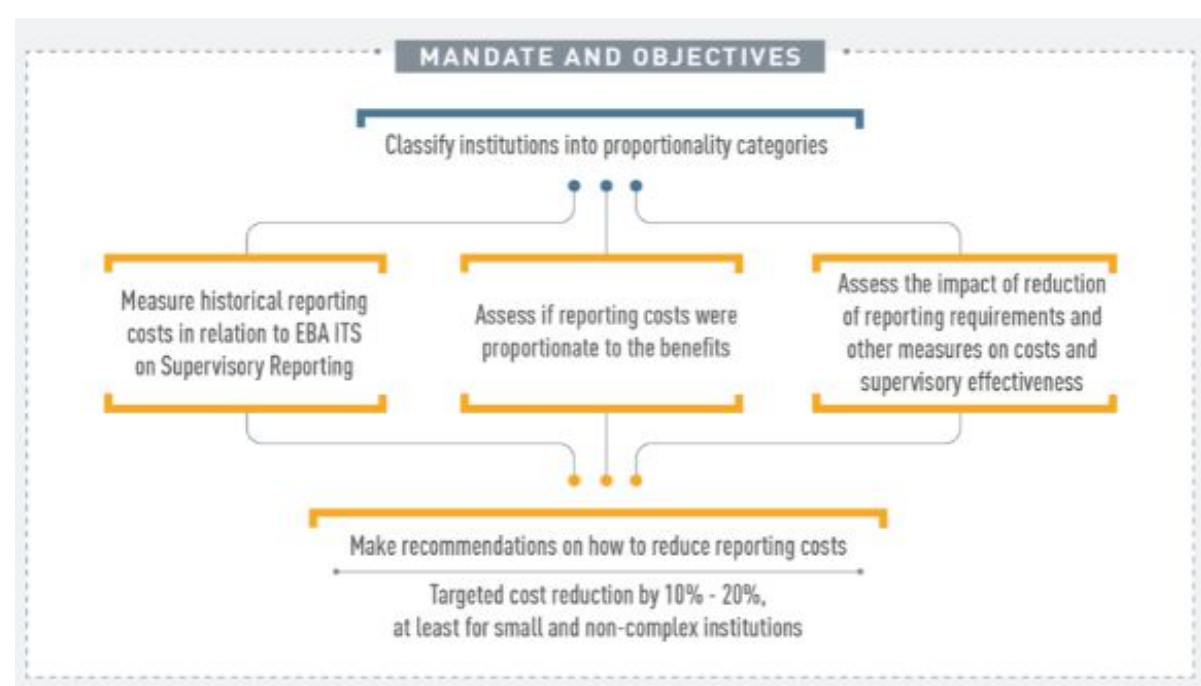

Figure 4. Initiative Cost of compliance with supervisory reporting

Source: European Banking Authority

To the above mentioned subject of analysis, can be added the point of view of the European Banking Federation, which mentions some of the benefits emerging from the use of distributed ledger technology (knows also as blockchain): "enhance supervision, improve transparency over transactions, enable new and smart ways to 
exchange information between entities and supervisors, increase flexibility and efficiency for both industry and authorities [12]". Indirectly can be seen an industry statement, in which, blockchain can be perceived as a possible platform where banks can save and share information regarding customer data, accomplishing the requirements of regulators, preventing the penalties for misconduct and have the historical content saved.

Blockchain technology can be used as well as a trading platform allowing settlement of securities in faster time and at lower costs. Such a proof of concept has been done recently on the German financial market in a joint effort by several public authorities. Quoting the original source the Deutsche Bundesbank [13] can be mentioned: "Deutsche Börse, Deutsche Bundesbank and Germany's Finance Agency have developed and successfully tested a settlement interface for electronic securities, working with a range of other market participants. Securities settlement using distributed ledger technology (DLT) is performed with the aid of a "trigger" solution and a transaction coordinator in TARGET2, the Euro system's large-value payment system".

One other area where the implementation of Blockchain has a clear advantage is the reconciliation of items, widely spread across several bank functions or processes: correspondent banking, accounting, treasury and finance, securities, payments and many others. Such an implementation would reduce significantly the operational costs, diminish the level of physical effort of some processes, allow availability of data and guarantee the interoperability of various data bases.

Italian Banking Association (known as ABI) through its ABI Laboratory has tested on a large scale the benefits of distributed ledger technology inside the reconciliation process for the items related to Italian banking system [14]. Known as project Spunta Banca DLT, the initiative developed gradually and has arrived to be seen not only as a strategic characteristic linked to the functioning of the Italian Banking System, but has started in being promoted as a valuable lesson learned experience inside the EU financial area. Based on the available information, 97 banks enlisted in the project, summing up $91 \%$ of employees present in the Italian Banking System [15].

The increased number of strong points is attracting the attention, enriching the qualitative area of the banking process as such:

- "assurance on the common criteria for the matching due to common rules on the ledger;

- inversion of reconciliation simplified (with only one click);

Year XXIV no. 80

June 2021 
- integrated communication with attachments;

- decreased operational risk;

- increased investigation process;

- standardized process;

- change from monthly reconciliation to daily reconciliation for all the reports;

- dashboard with global view available;

- autonomy in data extraction;

- increased availability level for CFO reporting [16]".

A reaserch paper from International Finance Corporation, part of World Bank Group mentions a clear advantage in the Trade Finance environment, a banking area marked by formality and increased processing times [17]. This statement comes to support a market estimated at several trillion per year, inside the same study, which can be seen as a normal consequence of the world trade relations in place. With blockchain, smart contracts can be used, and all the parties will have available the information much faster in a transparent way, while the latest version of the documents will be processed and published, eliminating some of the operational risk.

Another area were a bank would be interested in testing the technology is represented by the registration of its assests and exchange of content inside the organization itself or outside of it, with customers, other banks and public authorities. Such a direction is highly encouraged for European banks, with the current Global Data Protection Regulation in place or other provisions towards privacy. Blockchain technology allows criptography of data, security of content and utilization of permission levels, being in presence of public or private blockchains.

\section{Conclusions}

From the cases presented above can be understood the multiple directions available for the EU banks to follow and implement in the portfolio of their products and services. Nevertheless, it can be stated, that the opportunities offered by the blockchain technology are still to be identified and it is a journey to be started or to be continued by the different European banks, taking into consideration their openness and strategy on short, medium or long term.

Blockchain, like all the other aspects of innovation and technological development is putting its mark on the evolution of banks. Considering the general trend brought by the new technologies, financial actors are in front of key decisions to be taken, to address with more vision and flexibility the increased competitiveness of 
other financial actors and changing demands of customers, even with interest in shaping the content of services they buy.

The analysed technology offers a level of elasticity in its characteristics, a clear advantage, long time researched by the banks. This feature is represented by the capability to interact with other legacy systems or modular applications, allowing content exchange and analysis of information.

In times when the attention of regulatory bodies is directed towards the security of information, prevention of data breach, compliance with laws and regulations, the banks should act in their benefit, through the utilisation of blockchain. Many of the clients still address to banks for their financial requirements considering the level of privacy and confidence offered by the credit institutions. The blockchain can come on top of all of that and offer additional protection and security of data content, in fact, one of the strategic assets of our times.

At European level we may witness a further decrease in the number of credit institutions or even of the banking staff figures. This should not have necessarily a negative side, as specialized personnel could be directed towards new businesses based on blockchain technology or other emerging economic fields.

In closing of this paper is mentioned the position of European Banking Federation on the use of blockchain and distributed ledger technology "EBF believes that DLT has the potential to contribute positively to citizens' welfare and economic development. It has a considerable impact on banking industry infrastructures, roles and functions of financial intermediaries, back-office related securities processes, communication, interoperability and competition [18]".

\section{References}

European Banking Federation, 2020. "Banking in Europe: EBF Facts and Figures 2020 ", page 5, figures linked to 2019 data

European Banking Federation, 2020. "Banking in Europe: EBF Facts and Figures 2020", page 5, figures linked to 2019 data

European Banking Federation, 2020. "Banking in Europe: EBF Facts and Figures 2020", page 7, figures linked to 2019 data

Yaga D., Mell P., Roby N., Scarfone K., National Institute of Standards and Technology, US Department of Commerce, 2018, "Blockchain Technology Overview", page 13. Retrieved from https://csrc.nist.gov/publications/ detail/nistir/8202/final

Year XXIV no. 80

June 2021 
Nakamoto S., Bitcoin: A Peer-to-Peer Electronic Cash System, page 2

European Commission, 2018, "European Commission launches the EU Blockchain Observatory and Forum", Retrieved from https://ec.europa.eu/commission/presscorner/detail/en/IP_18_521

R3, "Who we are", Retrieved from: https://www.r3.com/about/

ABILab, "Spunta Banca DLT", Retrieved from https://www.abilab.it/areericerca/blockchain-dlt/spunta-banca-dlt

European Commission. "Banking and Finance Newsletter. Instant payments", Internet Source: https://ec.europa.eu/newsroom/fisma/item-detail.cfm? item_id $=654172 \& u t m \_s o u r c e=$ fisma_newsroom\&utm_medium $=$ Website $\&$ utm_campaign $=$ fisma\&utm_content $=$ Instant $\% 20$ payments $\% 20 \&$ lang $=$ en.

European Central Bank. Speech "From the payments revolution to the reinvention of money" by Fabio Panetta, Member of the Executive Board of the ECB, at the Deutsche Bundesbank conference on the "Future of Payments in Europe", Frankfurt am Main, 27 November 2020, Retrieved from https://www.ecb.europa.eu/press/key/date/2020/html/ecb.sp201127 a78 $1 \mathrm{c} 4 \mathrm{e} 0 \mathrm{fc} . \mathrm{en} . \mathrm{html}$

European Banking Authority, "Cost of compliance with supervisory reporting", Retrieved from https://www.eba.europa.eu/regulation-and-policy/ supervisory-reporting/cost-compliance-supervisory-reporting

European Banking Federation, "Distributed Ledger Technology", Retrieved from https://www.ebf.eu/priorities/innovation-cybersecurity/distributed-ledgertechnology-crypto-assets/

Deutsche Bundesbank, "DLT-based securities settlement in central bank money successfully tested", Retrieved from: https://www.bundesbank.de /en/press/press-releases/dlt-based-securities-settlement-in-central-bankmoney-successfully-tested-861444

ABILab, "Spunta Banca DLT", Retrieved from https://www.abilab.it/areericerca/blockchain-dlt/spunta-banca-dlt

ABILab, "Spunta Banca DLT", Retrieved from https://www.abilab.it/areericerca/blockchain-dlt/spunta-banca-dlt

ABILab, "Spunta Banca DLT", page 11

International Finance Corporation, World Bank Group, "BLOCKCHAIN. Opportunities for Private Enterprises in Emerging Markets", 2019, page 34

European Banking Federation, "EBF position \& key documents on Distributed Ledger Technology", Retrieved from https://www.ebf.eu/priorities/ innovation-cybersecurity/distributed-ledger-technology-crypto-assets/ 